\title{
Competing Effects of Renin Angiotensin System Blockade and Sodium-Glucose Cotransporter-2 Inhibitors on Erythropoietin Secretion in Diabetes
}

\author{
Katerina P. Marathias ${ }^{\text {a }}$ Vaia A. Lambadiari ${ }^{\text {b }}$ Konstantinos P. Markakis ${ }^{b}$ \\ Vassilios D. Vlahakos ${ }^{c}$ Dimitra Bacharaki ${ }^{b}$ Athanasios E. Raptis ${ }^{b}$ \\ George D. Dimitriadis ${ }^{b}$ Demetrios V. Vlahakos ${ }^{b}$ \\ a Onassis Cardiac Surgery Center, Athens, Greece; ${ }^{b}$ 2nd Department of Internal Medicine-Propaedeutic, Research \\ Institute and Diabetes Centre, Attikon University Hospital, National and Kapodistrian University of Athens Medical \\ School, Athens, Greece; ' Department of Pulmonary and Critical Care Services, Evangelismos Hospital, Athens, \\ Greece
}

\section{Keywords}

Angiotensin converting enzyme inhibitors - Angiotensin receptor blockers - Sodium-glucose cotransporter-2 inhibitors · Hematocrit · Haemoglobin

\begin{abstract}
Background: Anaemia is a common finding in diabetes, particularly in those patients with albuminuria or renal dysfunction and is associated with impaired erythropoietin (EPO) secretion. This review focuses on mechanisms involved in the regulation of erythropoiesis in diabetic patients in an effort to elucidate the competing effects of the renin angiotensin system (RAS) blockade and sodium-glucose cotransporter-2 (SGLT2) inhibitors on haemoglobin concentration and hematocrit values. Summary: The RAS shows significant activation in diabetic subjects. Angiotensin II, its active octapeptide, causes renal tubulointerstitial hypoxia, which stimulates hypoxia-inducible factors (HIF) and increases EPO secretion and erythropoiesis. As expected, drugs that inactivate RAS, such as angiotensin converting enzyme inhibitors or angiotensin receptor blockers (ACEi/ARB) are associated with a significant hematocrit-lowering effect and/or anaemia in various clinical conditions, including diabetes. Dual
\end{abstract}

blockade by a combination of ACEi and ARB in diabetic patients achieves a better RAS inhibition, but at the same time a worse drop of haemoglobin concentration. Increased glucose reabsorption by SGLTs in diabetic subjects generates a high-glucose environment in renal tubulointerstitium, which may impair HIF-1, damage renal erythropoietin-producing cells (REPs) and decrease EPO secretion and erythropoiesis. SGLT2 inhibitors, which inhibit glucose reabsorption, may attenuate glucotoxicity in renal tubulointerstitium, allowing REPs to resume their function and increase EPO secretion. Indeed, EPO levels increase within a few weeks after initiation of therapy with all known SGLT2 inhibitors, followed by increased reticulocyte count and a gradual elevation of haemoglobin concentration and hematocrit level, which reach zenith values after 2-3 months. Key Messages: The competing effects of RAS blockade and SGLT2 inhibitors on erythropoiesis may have important clinical implications. The rise of hematocrit values by SGLT2 inhibitors given on top of RAS blockade in recent outcome trials may significantly contribute to the cardiorenal protection attained. The relative contribution of each system to erythropoiesis and outcome remains to be revealed in future studies.

(c) 2020 S. Karger AG, Base

\section{KARGER}

(C) 2020 S. Karger AG, Basel

karger@karger.com

www.karger.com/ajn
Demetrios V. Vlahakos, MD

2nd Department of Internal Medicine-Propaedeutic, Research Institute and Diabetes Centre National and Kapodistrian University of Athens Medical School

Attikon University Hospital, 1 Rimini Street, Haidari, GR-12462 Athens (Greece)

E-Mail vlahakos@otenet.gr 


\section{Introduction}

Obesity and type 2 diabetes mellitus (T2DM) are increasing steadily worldwide and have reached epidemic proportions $[1,2]$. Diabetic kidney disease (DKD) is considered to be the leading cause of end-stage renal disease in the industrialized societies [3]. Anaemia is a common finding in patients with diabetes, particularly in those with albuminuria or renal impairment. At least 1 in 5 diabetic patients followed in tertiary outpatient clinics have anaemia. This association is most pronounced in patients with $\mathrm{DKD}$, where anaemia affects nearly half of them. Of note, anaemia is found earlier and is more severe in patients with DKD than in those with non-DKD, and its presence markedly increases the risk for microvascular and macrovascular complications [4-7]. Pathogenetic mechanisms thought to be responsible for the increased prevalence and severity of anaemia in diabetes have included the widespread use of renin angiotensin system (RAS) inhibitors, hyporeninemia, chronic inflammation, hypogonadotrophic hypogonadism with low serum testosterone levels in male diabetic patients and above all impaired erythropoietin (EPO) secretion attributed to tubulointestitial damage and/or autonomic neuropathy. Interestingly, $70 \%$ of anaemic patients with diabetes without renal impairment also have inappropriately low EPO levels [814].

EPO is an indispensable erythropoietic hormone primarily produced from peritubular fibroblasts in the renal cortex, the so-called renal erythropoietin-producing cells (REPs) and is tightly regulated in a hypoxia-inducible manner to maintain tissue oxygen homeostasis. Its production is controlled at the transcriptional level. Hypoxia increases EPO production and secretion by attenuating the inhibition of the EPO promoter by GATA2 and by supporting the availability of heterodimeric $(\alpha / \beta)$ hypoxia-inducible transcription factors (HIFs). Circulating EPO acts in the bone marrow, as an anti-apoptotic factor and allows survival, proliferation and differentiation of erythrocytic progenitors. Insufficient EPO production by REPs causes renal anaemia and anaemia associated with chronic disorders [15]. Recent studies have broadened our understanding of REPs from prototypic hypoxia-responsive cells to dynamic fibrogenic cells, which in chronic kidney disease (CKD), are the major source of scarforming myofibroblasts and actively produce fibrogenic molecules, including inflammatory cytokines, rather than EPO [16].

\section{The RAS and Erythropoiesis}

\section{The Activation of RAS Is Associated with Enhanced Erythropoiesis}

In most hypertensive subjects with T2DM, the RAS shows significant activation, and it is poorly suppressed, even in high salt diets [17]. There are many possible mechanisms underlying RAS activation in diabetes. First, the avid glucose reabsorption in the proximal tubule of the subjects with diabetes is coupled with avid sodium reabsorption by sodium-glucose co-transporters (SGLTs), the so-called SGLTs. This results in decreased distal sodium delivery to the macula densa and increased renin release [18]. Second, a growing body of experimental evidence suggests that insulin itself can cause RAS activation in subjects with metabolic syndrome or diabetes that have insulin resistance and hyperinsulinemia. Even in healthy volunteers, acute hyperinsulinemia increased renin and circulating angiotensin II (Ang II) levels [19, 20]. Finally, GPR91 (G protein-coupled receptor 2)-mediated paracrine signaling pathway in the juxtaglomerular apparatus may serve as a link between diabetes, RAS activation and systemic hypertension [21].

Ang II is a relatively selective vasoconstrictor of the efferent arterioles. Therefore, Ang II is expected to increase intraglomerular pressure and filtration fraction, while at the same time to decrease oxygen delivery to the tubulointerstitium via the postglomerular peritubular capillary bed. Additionally, Ang II exerts a dose-dependent direct stimulatory effect on proximal sodium reabsorption, thus enhancing the oxygen demand of tubular cells. Therefore, after RAS activation, the amalgamation of decreased oxygen supply and increased oxygen demand in the tubulointerstitium causes parenchymal hypoxia, which triggers EPO secretion (Fig. 1) [22]. Ang II can also stimulate EPO secretion by directly affecting HIFs. In this regard, HIF-1 expression, at both the messenger RNA and protein levels, is stimulated by adding Ang II in human placental explant cultures [23]. Moreover, Ang II is a growth factor that can directly stimulate the erythroid progenitors in the bone marrow to produce erythrocytes [24], while at the same time alters the expression of hepcidin and iron transporters to facilitate iron absorption and utilization [25].

\section{RAS Blockade Is Associated with Lowering of}

Hematocrit Values and/or Anaemia

Pharmacological interruption of RAS by angiotensin converting enzyme inhibitors or angiotensin receptor 


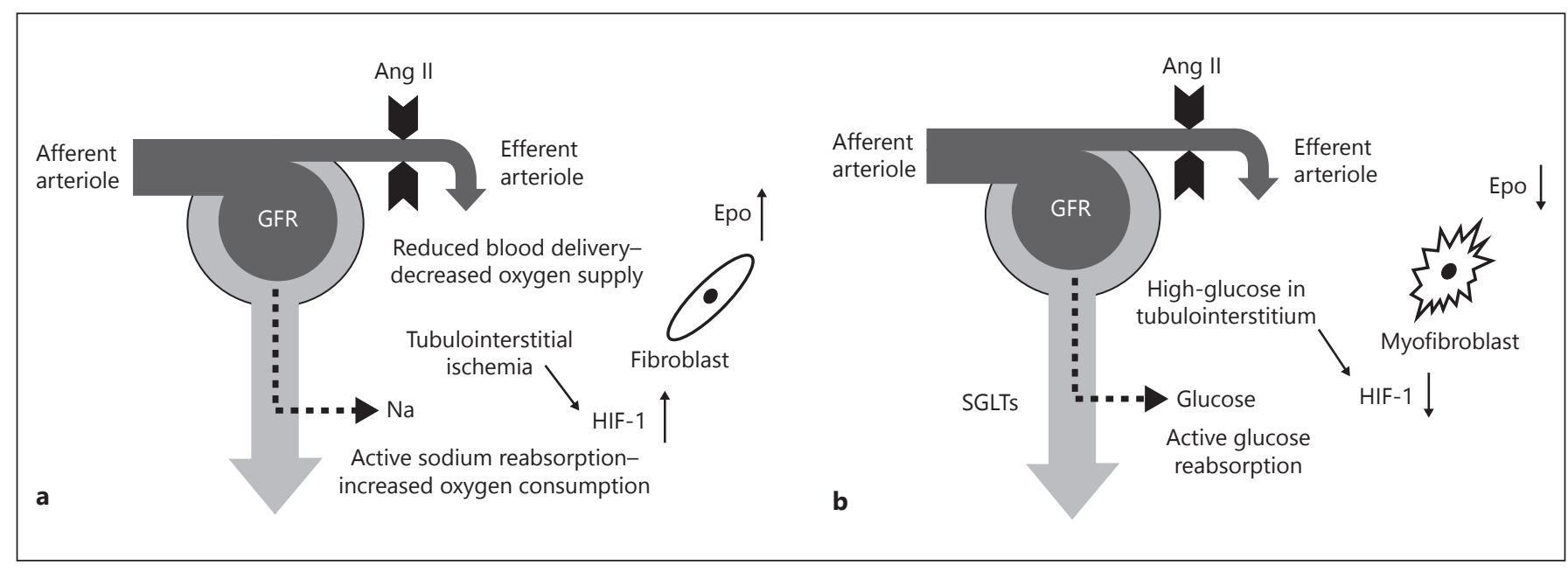

Fig. 1. Competing effects of Ang II and avid glucose reabsorption by SGLTs on EPO secretion in diabetic patients. a Ang II selectively constricts the efferent arterioles, increases intraglomerular pressure and glomerular filtration rate, while at the same time decreases oxygen delivery to the tubulointerstitium. Additionally, Ang II exerts a direct stimulatory effect on proximal sodium reabsorption, thus enhancing the oxygen demand of tubular cells. The amalgamation of decreased oxygen supply and increased oxygen demand causes tubulointerstitial hypoxia, HIF-1 activation and

blockers (ACEi/ARB), as part of the treatment algorithms in hypertensive, cardiac and renal patients with T2DM has been proven beneficial by several landmark studies. If RAS up-regulates erythropoiesis, as discussed above, it should be expected that drugs or modalities inactivating RAS may induce a hematocrit-lowering effect and/or anaemia. For instance, administration of renin or Ang II in experimental animals causes increased EPO secretion. Captopril blocks the renin- but not the Ang II-induced EPO secretion in rats, while losartan blocks the Ang IIinduced EPO secretion in normal volunteers [26-29]. Knockout mice for the ACE or angiotensinogen genes develop substantial anaemia, which is corrected by infusion of Ang II for 2 weeks [30, 31].

RAS contribution to erythropoiesis may be imperceptible in normal or near normal conditions, such as in uncomplicated hypertensive subjects with T2DM [32], but it is exaggerated when bone marrow requires all available stimuli to augment erythropoiesis, such as in patients with severe renal insufficiency, congestive heart failure or immunosuppression (Table 1). Administration of ACEi/ ARB is capable to normalize hematocrit values in individuals with altitude polycythemia, post-transplant erythrocytosis or polycythemia associated with COPD [3335]. In the SOLVD study including patients with heart

Effects of RAS Blockade and SGLT2

Inhibitors on Erythropoiesis increased EPO secretion by the peritubular fibroblasts (REPs). b Glomerular hyperfiltration in diabetic patients increases glucose load that is filtered and reabsorbed daily in the proximal tubules by SGLTs. This creates a high-glucose tubulointerstitial environment, which decreases HIF-1, damages and transforms REPs into myofibroblasts and causes reduced EPO secretion. Ang II, Angiotensin II; GFR, glomerular filtration rate; EPO, erythropoietin; HIF, hypoxia-inducible factors; SGLTs, sodium-glucose co-transporters.

failure randomized to enalapril or placebo, the odds of incident anaemia due to enalapril therapy increased by approximately $50 \%$ [36]. In a community study on anaemia and heart failure, the prevalence of anaemia increased by an estimated $16 \%$ between 1979 before the discovery of RAS inhibitors and 2002, when RAS inhibition was a cornerstone treatment modality ( $p=0.008)$ [37]. In patients with CKD, RAS inhibition decreased haemoglobin levels on the order of $0.6-0.9 \mathrm{~g} / \mathrm{dL}$. In contrast, no changes in haemoglobin concentrations occurred in patients with $\mathrm{CKD}$ receiving conventional anti-hypertensive drugs [38].

Similar results have been reported in subjects with diabetes treated with ACEi or ARBs. A post hoc analysis of the RENAAL study, which included patients with T2DM and DKD for an average follow-up period of 3.4 years showed that, compared with placebo, losartan treatment was associated with a significant decrease of haemoglobin concentration [39]. A subanalysis of the PAERI study comparing 3,361 patients with DKD with 1,861 patients with non-diabetic CKD found that the diabetic patients were treated more often with ACEi (73.9 vs. $55.4 \%, p<0.0001)$ and had a higher prevalence of anaemia (52.7 vs. $39.4 \%, p<0.0001$ ) [40]. Dual blockade by ACEi and ARB may achieve better RAS blockade, while 
Table 1. Hematocrit-lowering effect of RAS blockade may be imperceptible in normal or uncomplicated subjects [32], but it is exaggerated when bone marrow requires all available stimuli to augment erythropoiesis, such as in patients with CKD with or without diabetes, heart failure or immunosuppression

\begin{tabular}{|c|c|c|c|c|c|c|}
\hline Reference, year & $\begin{array}{l}\text { Number of } \\
\text { patients }\end{array}$ & $\begin{array}{l}\text { Hct } \\
\text { pre, } \%\end{array}$ & $\begin{array}{l}\text { Hct } \\
\text { post, \% }\end{array}$ & Clinical condition & Drug & $\begin{array}{l}\text { Duration, } \\
\text { months }\end{array}$ \\
\hline Kamper and Nielsen [38], 1990 & 27 & 36.7 & 32.4 & Adults with CKD & Enalapril & 3 \\
\hline Vlahakos et al. [62], 1991 & 10 & 42.0 & 33.0 & Renal transplant recipients & Enalapril & 3 \\
\hline Gaston et al. [63], 1991 & 12 & 57.0 & 47.0 & Post-transplant erythrocytosis & Enalapril & 9 \\
\hline Barr et al. [65], 1997 & 41 & 41.4 & 37.7 & Early heart failure & Enalapril & 12 \\
\hline Mazzali and Filho [66], 1998 & 27 & 56.0 & 46.0 & Post-transplant erythrocytosis & Enalapril & 3 \\
\hline Vlahakos et al. [35], 2001 & 9 & 56.0 & 46.0 & COPD with polycythemia & Losartan & 1 \\
\hline Plata et al. [33], 2002 & 13 & 63.5 & 56.8 & Altitude polycythemia & Enalapril & 12 \\
\hline Wuhl et al. [68], 2004 & 352 & 36.6 & 34.8 & Children with CKD & Ramipril & 6 \\
\hline Ogawa et al. [41], 2007 & 72 & 35.7 & 30.0 & $\mathrm{DKD}$ & $\begin{array}{l}\text { Temocapril and } \\
\text { candesartan }\end{array}$ & 12 \\
\hline
\end{tabular}

RAS, renin angiotensin system; CKD, chronic kidney disease; T1DM, type 1 diabetes mellitus; DKD, diabetic kidney disease; Hct, hematocrit; COPD, chronic obstructive pulmonary disease.

at the same time may be associated with a worse deterioration of haemoglobin concentration. A 24-week study in patients with $\mathrm{DKD}$, revealed that the group receiving a combination of temocapril with candesartan had a more intense anti-proteinuric effect and at the same time a more profound drop in hematocrit values from $35 \pm 4.7 \%$ at baseline to $30 \pm 4.6 \%$ at the end of the study, compared to the group receiving a combination of temocapril with amlodipine, whose hematocrit values dropped from $36.7 \pm 3.6 \%$ at baseline to $34.3 \pm 4.5 \%$ at the end of the study [41]. Similar observations were reported by Jacobsen et al. [42] in patients with T1DM treated with benazepril, valsartan or their combination. Benazepril and valsartan were equally effective in blocking RAS (PRA increased from $30 \mu \mathrm{U} / \mathrm{L}$ during placebo to 161 and $163 \mu \mathrm{U} / \mathrm{L}$ respectively) and in decreasing haemoglobin concentrations (from $8.5 \mathrm{mmol} / \mathrm{L}$ with placebo to 8.2 and $8.1 \mathrm{mmol} / \mathrm{L}$ respectively), whereas dual blockade by benazepril and valsartan achieved a better RAS blockade (PRA increased to $331 \mu \mathrm{U} / \mathrm{L}$ ), but a worse drop of haemoglobin to $7.8 \mathrm{mmol} / \mathrm{L}$.

\section{The SGLTs and Erythropoiesis}

\section{The Role of SGLTs in EPO Secretion}

In normal physiology, the kidneys play an important role in the regulation of glucose homeostasis via glucose utilization, glucose production and glucose reabsorption. The kidneys take $\sim 10 \%$ of all glucose utilized by the body and along with the liver are the only organs that are able to release glucose through gluconeogenesis [43]. The contribution of kidneys to overall gluconeogenesis accounts for 20-25\% [44]. Regarding glucose reabsorption, glucose is freely filtered in the Bowman's space and is returned to the circulation via 2 SGLTs, specifically SGLT2 (which contributes to $90 \%$ of all glucose reabsorbed) and SGLT-1 (10\% contribution) both located in the brush border of the proximal convoluted tubules. Renal tubular reabsorption of glucose is an active process, and if their capacity is exceeded, the transporters are unable to reabsorb the excess filtered glucose and glucosuria occurs.

In a healthy person, with plasma glucose levels $\sim 100$ $\mathrm{mg} / \mathrm{dL}$ and a glomerular filtration rate of $125 \mathrm{~mL} / \mathrm{min}$, 
Table 2. A modest increase in hematocrit values by $2-4 \%$ points is consistently observed following administration of all 6 gliflozins (empagliflozin, canagliflozin, dapagliflozin, ipragliflozin, ertugliflozin and sotagliflozin)

\begin{tabular}{lccllll}
\hline Reference, year & $\begin{array}{l}\text { Number of } \\
\text { patients }\end{array}$ & $\begin{array}{l}\text { Hct pre, } \\
\%\end{array}$ & $\begin{array}{l}\text { Hct post, } \\
\%\end{array}$ & Clinical condition & $\begin{array}{c}\text { Drug } \\
\text { months }\end{array}$ \\
\hline Zinman et al. [69], 2015 & 7,020 & 41.20 & 46.00 & T2DM at high CV risk & Empagliflozin & 30 \\
\hline Januzzi et al. [70], 2017 & 450 & 41.00 & 43.00 & Older subjects with T2DM & Canagliflozin & 25 \\
\hline Kimura et al. [52] 2018 & 31 & 39.10 & 41.70 & T2DM and hypertension & Ipragliflozin & 3 \\
\hline Maruyama et al. [56], 2019 & 9 & 37.10 & 40.40 & T2DM with anemia & Canagliflozin 3 \\
\hline van Raalte et al. [71], 2019 & 1,049 & 42.00 & 44.00 & T1DM & Sotagliflozin & 13 \\
\hline Gallo et al. [72], 2019 & 199 & 42.12 & 45.13 & T2DM & Ertugliflozin 3 \\
\hline van Bommel et al. [73], 2020 & 24 & 40.70 & 42.50 & T2DM & Dapagliflozin 3 \\
\hline
\end{tabular}

T1DM, type 1 diabetes mellitus; T2DM, type 2 diabetes mellitus; Hct, hematocrit; CV, cardiovascular.

$180 \mathrm{~g}$ of glucose are filtered and reabsorbed daily. In T1DM and T2DM individuals, hyperglycaemia increases filtered glucose load. For example, in a subject with diabetes and average plasma glucose level of $200 \mathrm{mg} / \mathrm{dL}$ and hyperfiltration (glomerular filtration rate $160 \mathrm{~mL} / \mathrm{min}$ ), a huge amount of glucose $(\sim 460 \mathrm{~g})$ is filtered and reabsorbed daily [45]. The molecular mechanism responsible for increased renal glucose reabsorption during hyperglycaemia involves an increase in the expression of glucose transporter genes in the proximal tubule. Renal tubular cells isolated from the urine of subjects with T2DM have an increase in the expression of SGLT2 mRNA and protein and demonstrate enhanced capability of glucose transport [46]. The local high-glucose environment in renal tubulointerstitium due to the increased glucose reabsorption by SGLTs in diabetes may directly and indirectly damage REPs and diminish EPO production (Fig. 1). First, high-glucose concentration can impair hypoxia-dependent protection of HIF-1 against proteasomal degradation and interferes with cellular responses to hypoxia in diabetic patients [47]. Second, hyperglycaemia can stimulate renal tubular epithelial cells to produce pro-inflammatory molecules that could negatively affect the neighbouring peritubular REPs. Incubation of human renal proximal tubular epithelial cells (HK-2) in high glucose concentration activates the p38 mitogen-activated protein kinases pathway and the nuclear factor- $\mathrm{\kappa B}$, and increases the production of pro-inflammatory cytokines, such as tumour necrosis factor- $\alpha$, interleukin-1 (IL-1) and IL-6 [48]. Both IL-1 and tumour necrosis factor- $\alpha$ were found capable to suppress EPO gene expression in isolated perfused rat kidneys and in human hepatoma cell cultures, whereas IL-6 can inhibit EPO synthesis in the kidney [49].

\section{SGLT2 Inhibitors Are Associated with Increased EPO} Secretion and Hematocrit Values

As shown in Table 2, a significant rise of haemoglobin concentration and hematocrit values has been consistently noted in patients treated with various SGLT inhibitors, even in patients without diabetes. In the beginning, these phenomena were thought to be initiated by the diuretic action of SGLT-2 inhibitors causing hemoconcentration, but this does not seem to be the only explanation. First, in a pioneer trial with T2DM, treatment with dapagliflozin was associated with a reduction in plasma volume of approximately $7 \%$ along with an increase in plasma renin activity and serum aldosterone levels. Of particular interest, however, in the same trial, a true augmentation of erythropoiesis was revealed in the dapagliflozin group, as evidenced by transient elevations in serum EPO levels and reticulocyte counts that preceded the rise of hematocrit by $2.2 \%$ points, haemoglobin by 0.6 $\mathrm{g} / \mathrm{dL}$ and red blood cell mass by $6 \%$ [50]. In another study, urine volume increased within $24 \mathrm{~h}$ after the initiation of treatment with SGLT-2 inhibitors, but returned to baseline within a week. The body fluid status, as measured by total and extracellular water and reflected in renin and aldosterone levels remained stable thereafter [51]. Second, more potent diuretics, such as thiazide and loop diuretics are not associated with sustained increase in hematocrit values despite decreasing body fluid volume. In fact, switching patients from thiazide diuretics to the SGLT-2 inhibitor ipragliflozin was accompanied by an 
increase in haemoglobin concentration from $12.9 \pm 1.6$ to $13.6 \pm 1.8 \mathrm{~g} / \mathrm{dL}$ and hematocrit values from $39.1 \pm 4.3$ to $41.7 \pm 4.9 \%$ points after 3 months [52]. Finally, diuretics of loop of Henle, distal tubule and collecting duct (furosemide, hydrochlorothiazide, and amiloride, respectively) do not seem to affect EPO production, whereas diuretics acting predominantly at the proximal tubular site, such as acetazolamide, significantly reduce the EPO production in response to hypoxia in mice [53].

In comparison, SGLT2 inhibitors seem to actively stimulate the erythropoietic process. For example, in a randomized controlled trial comparing the effects of dapagliflozin and DPP-4 inhibitors in T2DM, a significant elevation of haemoglobin concentration and hematocrit values was noted with dapagliflozin treatment. EPO levels increased after initiation of dapagliflozin treatment and reached a plateau in 2-4 weeks. The reticulocyte count increased simultaneously, followed later on by the elevation of haemoglobin and hematocrit levels [54]. In a sub-study of the EMPA-HEART CardioLink-6 randomized clinical trial individuals with T2DM and stable coronary artery disease were randomized to either empagliflozin $10 \mathrm{mg}$ daily or placebo for 6 months. EPO levels increased significantly after 1 month of empagliflozin treatment. Hematocrit increased after 6 months by $2.34 \%$ points, associated with reduced ferritin levels and mean cell haemoglobin concentration [55]. Maruyama et al. [56] studied 9 subjects with diabetes administered canagliflozin $100 \mathrm{mg}$ qd for 12 weeks on top of standard treatment with conventional anti-diabetic drugs and RAS inhibitors. Serum EPO concentration increased by $38 \%$ between baseline and 2-4 weeks. Reticulocyte count transiently increased at 2 weeks followed by increased haemoglobin concentration (from $11.8 \pm 0.6 \mathrm{~g} / \mathrm{dL}$ at baseline to $12.9 \pm 1.1 \mathrm{~g} / \mathrm{dL}$, at study completion, $p=0.0049$ ), hematocrit values (from $37.1 \pm 2.3$ at baseline to $40.4 \pm 3.2 \%$ points, at study completion, $p=0.002$ ) and decreased serum ferritin levels $(p=0.003)$.

The mechanism(s) by which SGLT2 inhibitors augment erythropoiesis have not yet been fully elucidated. It is possible that the reduced glucose reabsorption in the proximal tubules by the action of SGLT2 inhibitors decreases highglucose accumulation in the renal tubulointerstitial microenvironment and attenuates glucotoxicity on various cells including REPs. Terami et al. [57] showed that dapagliflozin decreased macrophage infiltration and oxidative stress into the kidney of $\mathrm{db} / \mathrm{db}$ mice in a dose-dependent manner. Shin et al. [58] showed that dapagliflozin decreased the expression of tissue oxidative stress markers, inflammatory cell infiltration, mesangial widening, inter- stitial fibrosis and total collagen content in diabetic rats. In vitro work in human proximal tubular cells suggests that the SGLT-2 inhibitor, empagliflozin, reduces inflammatory and fibrotic markers induced by hyperglycaemia and may limit glucose-induced damage of the proximal tubule. The specific mode of action is thought to be blockage of glucose entry into the cell [59]. Finally, SGLT2 inhibitors could increase erythropoiesis by suppressing hepcidin production and modulating other iron regulatory proteins to facilitate iron absorption and utilization [60].

\section{Synthesis and Conclusions}

The competing nature of erythropoiesis in subjects with diabetes treated with RAS blockade and SGLT2 inhibitors emanates from the fact that RAS activation and avid glucose reabsorption by SGLTs exert opposing effects on renal tubulointerstitium. RAS activation that accompanies diabetes and in particular, Ang II augments erythropoiesis by causing tubulointerstitial ischemia, increasing EPO secretion, acting directly on erythroid progenitors, as growth factor and reducing hepcidin to facilitate iron absorption and utilization. On the other hand, activated SGLTs during hyperglycaemia in subjects with diabetes increase renal glucose reabsorption resulting in a local high-glucose tubulointerstitial environment, which directly and indirectly damage REPs and decrease EPO secretion. The opposite sequence of events is expected when inhibitors of RAS or SGLT2 are administered. RAS inhibitors are associated with a drop in EPO levels and a hematocrit-lowering effect or even anaemia, which actually carries an ominous and independent prognostic role in cardiac patients. For instance, in the Val-HeFT trial, an increased risk of death was found in the lower 2 compared to the upper 2 haemoglobin quartiles [61]. By contrast, SGLT2 inhibitors are associated with increased EPO secretion and a consistent elevation in hematocrit values and haemoglobin concentrations in patients already treated with RAS inhibitors. This beneficial effect might have important clinical implications, as revealed in a recent post hoc analysis of the EMPA-REG OUTCOME study, where the elevation of hematocrit values following empagliflozin treatment in patients with T2DM and coronary artery disease seemed to account for over half of the mortality benefit in comparison to placebo [55]. The relative contribution of each system to erythropoiesis remains to be revealed in future studies, in whom ACEi/ARB will be added in patients on SGLT2 inhibitors, or SGLT2 inhibitors will be administered on top of RAS blockade in a random or- 
der. It is worth mentioning, however, that in all major outcome studies with SGLT2 inhibitors, beneficial cardiorenal effects were observed in the study group, even if $>80 \%$ of participants were already treated with ACEi/ARB.

\section{Disclosure Statement and Funding Sources}

We have no conflicts of interest or funding sources to disclose.

\section{References}

1 Ogden CL, Carroll MD, Kit BK, Flegal KM. Prevalence of childhood and adult obesity in the United States, 2011-2012. JAMA. 2014 Feb;311(8):806-14.

2 US Renal Data System. USRDS 2012 annual data report: atlas of chronic kidney disease and end-stage renal disease in the United States. Bethesda: National Institutes of Health and National Institute of Diabetes and Digestive and Kidney Diseases, 2012. [Accessed Sep 13, 2013]. Available from: http://www.usrds. org/2012/pdf/v2_ch1_12.pdf.

3 Coresh J, Selvin E, Stevens LA, Manzi J, Kusek JW, Eggers P, et al. Prevalence of chronic kidney disease in the United States. JAMA. 2007 Nov;298(17):2038-47.

4 Alicic RZ, Rooney MT, Tuttle KR. Diabetic Kidney Disease: Challenges, Progress, and Possibilities. Clin J Am Soc Nephrol. 2017 Dec;12(12):2032-45.

5 Dikow R, Schwenger V, Schömig M, Ritz E. How should we manage anaemia in patients with diabetes? Nephrol Dial Transplant. 2002; 17 Suppl 1:67-72.

6 Thomas MC, MacIsaac RJ, Tsalamandris C, Power D, Jerums G. Unrecognized anemia in patients with diabetes: a cross-sectional survey. Diabetes Care. 2003 Apr;26(4):11649.

7 Deray G, Heurtier A, Grimaldi A, Launay Vacher V, Isnard Bagnis C. Anemia and diabetes. Am J Nephrol. 2004 Sep-Oct;24(5):522-6.

8 Astor BC, Muntner P, Levin A, Eustace JA, Coresh J. Association of kidney function with anemia: the third national health and nutrition examination survey (1988-1994). Arch Intern Med. 2002 Jun;162(12):1401-8.

9 Donnelly S, Shah BR. Erythropoietin deficiency in hyporeninemia. Am J Kidney Dis. 1999 May;33(5):947-53.

10 Means RT Jr, Krantz SB. Progress in understanding the pathogenesis of the anemia of chronic disease. Blood. 1992 Oct;80(7):163947.

11 Dhindsa S, Ghanim H, Batra M, Dandona P. Hypogonadotropic Hypogonadism in Men With Diabesity. Diabetes Care. 2018 Jul; 41(7):1516-25.

12 Ricerca BM, Todaro L, Caduto S, Cotroneo P, Damiani P, Manto A, et al. Blunted erythropoietin response to anemia in type 1 diabetic patients disease. Blood. 1992;80:163947.

13 Bosman DR, Winkler AS, Marsden JT, Macdougall IC, Watkins PJ. Anemia with erythropoietin deficiency occurs early in diabetic ne- phropathy. Diabetes Care. 2001 Mar;24(3): 495-9.

14 Winkler AS, Marsden J, Chaudhuri KR, Hambley $\mathrm{H}$, Watkins PJ. Erythropoietin depletion and anaemia in diabetes mellitus. Diabet Med. 1999 Oct;16(10):813-9.

15 Bunn HF. Erythropoietin. Cold Spring Harb Perspect Med. 2013 Mar;3(3):a011619.

16 Souma T, Suzuki N, Yamamoto M. Renal erythropoietin-producing cells in health and disease. Front Physiol. 2015 Jun;6:167.

17 Miller JA, Floras JS, Zinman B, Skorecki KL, Logan AG. Effect of hyperglycaemia on arterial pressure, plasma renin activity and renal function in early diabetes. Clin Sci (Lond). 1996 Mar;90(3):189-95.

18 Alicic RZ, Neumiller JJ, Johnson EJ, Dieter B, Tuttle KR. Sodium-Glucose Cotransporter 2 Inhibition and Diabetic Kidney Disease. Diabetes. 2019 Feb;68(2):248-57.

19 Shinozaki K, Ayajiki K, Nishio Y, Sugaya T, Kashiwagi A, Okamura T. Evidence for a causal role of the renin-angiotensin system in vascular dysfunction associated with insulin resistance. Hypertension. 2004 Feb;43(2):255-62.

20 Rooney DP, Edgar JD, Sheridan B, Atkinson $A B$, Bell PM. The effects of low dose insulin infusions on the renin angiotensin and sympathetic nervous systems in normal man. Eur J Clin Invest. 1991 Aug;21(4):430-5.

21 Peti-Peterdi J, Kang JJ, Toma I. Activation of the renal renin-angiotensin system in diabetes-new concepts. Nephrol Dial Transplant. 2008 Oct;23(10):3047-9.

22 Vlahakos DV, Marathias KP, Madias NE. The role of the renin-angiotensin system in the regulation of erythropoiesis. Am J Kidney Dis. 2010 Sep;56(3):558-65.

23 Takayuki Iriyama T, Wang W, Parchim NF, Song A, Blackwell SC, Sibai BM, et al. Hypoxia-independent upregulation of placental HIF-1 $\alpha$ gene expression contributes to the pathogenesis of preeclampsia. Hypertension. 2015;65(6):1307-15.

24 Mrug M, Stopka T, Julian BA, Prchal JF, Prchal JT. Angiotensin II stimulates proliferation of normal early erythroid progenitors. J Clin Invest. 1997 Nov; 100(9):2310-4.

25 Tajima S, Ikeda Y, Enomoto H, Imao M, Horinouchi Y, Izawa-Ishizawa Y, et al. Angiotensin II alters the expression of duodenal iron transporters, hepatic hepcidin, and body iron distribution in mice. Eur J Nutr. 2015 Aug;54(5):709-19.

26 Anagnostou A, Baranowski R, Pillay VK, Kurtzman N, Vercellotti G, Fried W. Effect of renin on extrarenal erythropoietin production. J Lab Clin Med. 1976 Nov;88(5):707-15.

27 Fried W, Barone-Varelas J, Barone T, Anagnostou A. Effect of angiotensin infusion on extrarenal erythropoietin production. J Lab Clin Med. 1982 Apr;99(4):520-5.

28 Gould AB, Goodman S, DeWolf R, Onesti G, Swartz C. Interrelation of the renin system and erythropoietin in rats. J Lab Clin Med. 1980 Sep;96(3):523-34.

29 Gossmann J, Burkhardt R, Harder S, Lenz T, Sedlmeyer A, Klinkhardt U, et al. Angiotensin II infusion increases plasma erythropoietin levels via an angiotensin II type 1 receptor-dependent pathway. Kidney Int. 2001 Jul;60(1):83-6.

30 Cole J, Ertoy D, Lin H, Sutliff RL, Ezan E, Guyene TT, et al. Lack of angiotensin II-facilitated erythropoiesis causes anemia in angiotensin-converting enzyme-deficient mice. J Clin Invest. 2000 Dec;106(11):1391-8.

31 Kato H, Ishida J, Matsusaka T, Ishimaru T, Tanimoto K, Sugiyama F, et al. Erythropoiesis and Blood Pressure Are Regulated via AT1 Receptor by Distinctive Pathways. PLoS One. 2015 Jun;10(6):e0129484.

32 Raptis AE, Bacharaki D, Mazioti M, Marathias KP, Markakis KP, Raptis SA, et al. Anemia due to coadministration of renin-angiotensin-system inhibitors and PPAR $\gamma$ agonists in uncomplicated diabetic patients. Exp Clin Endocrinol Diabetes. 2012 Jul;120(7): 416-9.

33 Plata R, Cornejo A, Arratia C, Anabaya A, Perna A, Dimitrov BD, et al.; Commission on Global Advancement of Nephrology (COMGAN), Research Subcommittee of the International Society of Nephrology. Angiotensin-converting-enzyme inhibition therapy in altitude polycythaemia: a prospective randomised trial. Lancet. 2002 Feb;359(9307): 663-6.

34 Vlahakos DV, Marathias KP, Agroyannis B, Madias NE. Posttransplant erythrocytosis. Kidney Int. 2003 Apr;63(4):1187-94.

35 Vlahakos DV, Marathias KP, Kosmas EN. Losartan reduces hematocrit in patients with chronic obstructive pulmonary disease and secondary erythrocytosis. Ann Intern Med. 2001 Mar; 134(5):426-7.

36 Ishani A, Weinhandl E, Zhao Z, Gilbertson DT, Collins AJ, Yusuf S, et al. Angiotensinconverting enzyme inhibitor as a risk factor for the development of anemia, and the impact of incident anemia on mortality in patients with left ventricular dysfunction. J Am Coll Cardiol. 2005 Feb;45(3):391-9.
Effects of RAS Blockade and SGLT2

Inhibitors on Erythropoiesis
Am J Nephrol 2020;51:349-356

DOI: $10.1159 / 000507272$ 
37 Dunlay SM, Weston SA, Redfield MM, Killian JM, Roger VL. Anemia and heart failure: a community study. Am J Med. 2008 Aug; 121(8):726-32.

38 Kamper AL, Nielsen OJ. Effect of enalapril on haemoglobin and serum erythropoietin in patients with chronic nephropathy. Scand J Clin Lab Invest. 1990 Oct;50(6):611-8.

39 Mohanram A, Zhang Z, Shahinfar S, Lyle PA, Toto RD. The effect of losartan on hemoglobin concentration and renal outcome in diabetic nephropathy of type 2 diabetes. Kidney Int. 2008 Mar;73(5):630-6.

40 Lorber D, Reddan D. Clinical characteristics of chronic kidney disease patients with and without diabetes: a subanalysis of the PAERI study. Clin Nephrol. 2006 Jul;66(1):11-6.

41 Ogawa S, Takeuchi K, Mori T, Nako K, Tsubono Y, Ito S. Effects of monotherapy of temocapril or candesartan with dose increments or combination therapy with both drugs on the suppression of diabetic nephropathy. Hypertens Res. 2007 Apr;30(4):325-34.

42 Jacobsen P, Andersen S, Jensen BR, Parving $\mathrm{HH}$. Additive effect of ACE inhibition and angiotensin II receptor blockade in type I diabetic patients with diabetic nephropathy. J Am Soc Nephrol. 2003 Apr;14(4):9929.

43 Gerich JE. Role of the kidney in normal glucose homeostasis and in the hyperglycaemia of diabetes mellitus: therapeutic implications. Diabet Med. 2010 Feb;27(2):13642.

44 Gerich JE, Meyer C, Woerle HJ, Stumvoll M. Renal gluconeogenesis: its importance in human glucose homeostasis. Diabetes Care. 2001 Feb;24(2):382-91.

45 Mather A, Pollock C. Glucose handling by the kidney. Kidney Int Suppl. 2011 Mar;120:S16.

46 Rahmoune $\mathrm{H}$, Thompson PW, Ward JM, Smith CD, Hong G, Brown J. Glucose transporters in human renal proximal tubular cells isolated from the urine of patients with noninsulin-dependent diabetes. Diabetes. 2005 Dec;54(12):3427-34.

47 Catrina SB, Okamoto K, Pereira T, Brismar K, Poellinger L. Hyperglycemia regulates hypoxia-inducible factor-1alpha protein stability and function. Diabetes. 2004 Dec;53(12): 3226-32.

48 Chen P, Yuan Y, Zhang T, Xu B, Gao Q, Guan T. Pentosan polysulfate ameliorates apoptosis and inflammation by suppressing activation of the p38 MAPK pathway in high glucose-treated HK-2 cells. Int J Mol Med. 2018 Feb;41(2):908-14.

49 Jelkmann W. Proinflammatory cytokines lowering erythropoietin production. J Interferon Cytokine Res. 1998 Aug;18(8):555-9.

50 Lambers Heerspink HJ, de Zeeuw D, Wie L, Leslie B, List J. Dapagliflozin a glucose-regulating drug with diuretic properties in subjects with type 2 diabetes. Diabetes Obes Metab. 2013 Sep;15(9):853-62.
51 Schork A, Saynisch J, Vosseler A, Jaghutriz BA, Heyne N, Peter A, et al. Effect of SGLT2 inhibitors on body composition, fluid status and renin-angiotensin-aldosterone system in type 2 diabetes: a prospective study using bioimpedance spectroscopy. Cardiovasc Diabetol. 2019 Apr;18(1):46.

52 Kimura T, Sanada J, Shimoda M, Hirukawa H, Fushimi Y, Nishioka M, et al. Switching from low-dose thiazide diuretics to sodiumglucose cotransporter 2 inhibitor improves various metabolic parameters without affecting blood pressure in patients with type 2 diabetes and hypertension. J Diabetes Investig. 2018 Jul;9(4):875-81.

53 Eckardt KU, Kurtz A, Bauer C. Regulation of erythropoietin production is related to proximal tubular function. Am J Physiol. 1989 May;256(5 Pt 2):F942-7.

54 Nomoto H, Miyoshi H, Sugawara H, Ono K, Yanagiya $S$, Oita $M$, et al. A randomized controlled trial comparing the effects of dapagliflozin and DPP-4 inhibitors on glucose variability and metabolic parameters in patients with type 2 diabetes mellitus on insulin. Diabetol Metab Syndr. 2017 Jul;9(1): 54.

55 Verma S, Mazer CD, Yan AT, Mason T, Garg $\mathrm{V}$, Teoh H, et al. Effect of Empagliflozin on Left Ventricular Mass in Patients With Type 2 Diabetes Mellitus and Coronary Artery Disease: The EMPA-HEART CardioLink-6 Randomized Clinical Trial. Circulation. 2019 Nov;140(21):1693-702.

56 Maruyama T, Takashima H, Oguma H, Nakamura Y, Ohno M, Utsunomiya K, et al. Canagliflozin Improves Erythropoiesis in Diabetes Patients with Anemia of Chronic Kidney Disease. Diabetes Technol Ther. 2019 Dec; 21(12):713-20.

57 Terami N, Ogawa D, Tachibana H, Hatanaka T, Wada J, Nakatsuka A, et al. Long-term treatment with the sodium glucose cotransporter 2 inhibitor, dapagliflozin, ameliorates glucose homeostasis and diabetic nephropathy in $\mathrm{db} / \mathrm{db}$ mice. PLoS One. 2014 Jun; 9(6):e100777.

58 Shin SJ, Chung S, Kim SJ, Lee EM, Yoo YH, Kim JW, et al. Effect of Sodium-Glucose CoTransporter 2 Inhibitor, Dapagliflozin, on Renal Renin-Angiotensin System in an Animal Model of Type 2 Diabetes. PLoS One. 2016;11(11):e0165703.

59 Panchapakesan U, Pegg K, Gross S, Komala MG, Mudaliar H, Forbes J, et al. Effects of SGLT2 inhibition in human kidney proximal tubular cells-renoprotection in diabetic nephropathy? PLoS One. 2013;8(2):e54442.

60 Ghanim H, Abuaysheh S, Hejna J, Green K, Batra M, Makdissi A, et al. Dapagliflozin Suppresses Hepcidin and increases erythropoiesis. J Clin Endocrinol Metab. 2020 Apr; 105(4):pii:dgaa057.

61 Anand IS, Kuskowski MA, Rector TS, Florea VG, Glazer RD, Hester A, et al. Anemia and change in hemoglobin over time related to mortality and morbidity in patients with chronic heart failure: results from Val-HeFT. Circulation. 2005 Aug;112(8):1121-7.

62 Vlahakos DV, Canzanello VJ, Madaio MP, Madias NE. Enalapril-associated anemia in renal transplant recipients treated for hypertension. Am J Kidney Dis. 1991 Feb;17(2):199-205.

63 Gaston RS, Julian BA, Diethelm AG, Curtis JJ. Effects of enalapril on erythrocytosis after renal transplantation. Ann Intern Med. 1991 Dec;115(12):954-5.

64 Herrlin B, Nyquist O, Sylvén C. Induction of a reduction in haemoglobin concentration by enalapril in stable, moderate heart failure: a double blind study. Br Heart J. 1991 Sep; 66(3):199-205.

65 Barr CS, Naas AA, Fenwick M, Struthers AD. Enalapril reduces QTc dispersion in mild congestive heart failure secondary to coronary artery disease. Am J Cardiol. 1997 Feb; 79(3):328-33.

66 Mazzali M, Filho GA. Use of aminophylline and enalapril in posttransplant polycythemia. Transplantation. 1998 Jun;65(11):1461-4.

67 Iodice C, Balletta MM, Minutolo R, Giannattasio P, Tuccillo S, Bellizzi V, et al. Maximal suppression of renin-angiotensin system in nonproliferative glomerulonephritis. Kidney Int. 2003 Jun;63(6):2214-21.

68 Wühl E, Mehls O, Schaefer F; ESCAPE Trial Group. Antihypertensive and antiproteinuric efficacy of ramipril in children with chronic renalfailure. Kidney Int. 2004 Aug;66(2):768-76.

69 Zinman B, Wanner C, Lachin JM, Fitchett D, Bluhmki E, Hantel S, et al.; EMPA-REG OUTCOME Investigators. Empagliflozin, Cardiovascular Outcomes, and Mortality in Type 2 Diabetes. N Engl J Med. 2015 Nov; 373(22):2117-28.

70 Januzzi JL Jr, Butler J, Jarolim P, Sattar N, Vijapurkar U, Desai M, et al. Effects of Canagliflozin on Cardiovascular Biomarkers in Older Adults With Type 2 Diabetes. J Am Coll Cardiol. 2017 Aug;70(6):704-12.

71 van Raalte DH, Bjornstad P, Persson F, Powell DR, de Cassia Castro R, Wang PS, et al. The Impact of Sotagliflozin on Renal Function, Albuminuria, Blood Pressure, and Hematocrit in Adults With Type 1 Diabetes. Diabetes Care. 2019 Oct;42(10):1921-9.

72 Gallo S, Charbonnel B, Goldman A, Shi H, Huyck S, Darekar A, et al. Long-term efficacy and safety of ertugliflozin in patients with type 2 diabetes mellitus inadequately controlled with metformin monotherapy: 104week VERTIS MET trial. Diabetes Obes Metab. 2019 Jan;21(4):1027-36.

73 van Bommel EJ, Muskiet MH, van Baar MJ, Tonneijck L, Smits MM, Emanuel AL, et al. The renal hemodynamic effects of the SGLT2 inhibitor dapagliflozin are caused by postglomerular vasodilatation rather than preglomerular vasoconstriction in metformintreated patients with type 2 diabetes in the randomized, double-blind RED trial. Kidney Int. 2020 Jan;97(1):202-12. 